\title{
Covid SeveriTy Score PREDICTOR 50: A novel scoring system to assess prognosis in COVID 19 illness
}

\author{
Vivek Gundappa ${ }^{1}$, Parinita Suresh ${ }^{2}$, Manjari Rajagopalan ${ }^{3}$ \\ ${ }_{1,2}$ Assistant Professor, ${ }^{3}$ Junior Resident Department of Pulmonary Medicine, Rajarajeswari Medical College and \\ Hospital, Bengaluru
}

Background: The first case of COVID 19 illness was detected on $31^{\text {st }}$ December 2019 and the disease has progressed globally causing significant morbidity and mortality. The disease initially thought to be a respiratory virus soon showed manifestations involving other systems and diagnosis and treatment of the disease became more complicated. This study aims to derive a scoring system based on health records of patients suffering from COVID 19, to help in early triaging of the illness and therefore allowing for early institution of treatment. Aims and Objective: To establish a scoring system inclusive of clinical, laboratory and radiological parameters to assist in the prognosis of patients afflicted with COVID 19 illness. Materials and Methods: Health records of 138 COVID patients has been included in the study. The scoring system comprises of parameters including Age, Co-morbidities, Shortness of breath, Saturation, Pulse Rate, Respiratory rate, temperature, D dimer, Neutrophil Lymphocyte ratio, Troponin I, Organ involvement, Radiology. The cumulative scoring ranges from 0-16. The mortality rate among the subjects included was $25.4 \%$. Results: All parameters involved were found to be independent risk factors for mortality. Patients were effectively categorized based on the scoring system and mortality found to be associated with increasing scores. This model displayed good discrimination ( $A \cup C=0.875$ ) and the sensitivity and specificity of the model was found to be 0.857 and 0.767 respectively. Conclusion: This scoring system has been designed to categorize based on the systemic involvement of the disease and thus would serve as a reliable indicator for prognostic assessment in patients.

Key words: COVID-19; Scoring; Mortality; Triaging
Access this article online

Website:

http://nepjol.info/index.php/AJMS DOI: 10.3126/ajms.v12i9.38428

E-ISSN: 2091-0576

P-ISSN: $2467-9100$

Copyright (c) 2021 Asian Journal of Medical Sciences

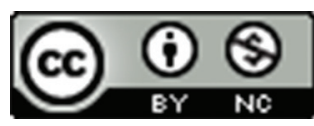

This work is licensed under a Creative Commons Attribution-NonCommercial 4.0 International License.

\section{INTRODUCTION}

The WHO declared a pandemic on the $11^{\text {th }}$ January 2020 of a respiratory illness now called the Coronavirus disease 2019. The first known case was found on December 1, 2019 in Wuhan, China. ${ }^{1}$ Initially thought to be a pneumonia of unknown origin in those exposed to the sea market in Wuhan, the disease spread globally causing one of the deadliest pandemics with $\sim 95 \%$ recoveries and 4.22 million deaths worldwide (as on $1^{\text {st }}$ August 2021). The causative virus behind the pandemic belonged to a group of respiratory viruses called the coronavirus. The disease spreads through respiratory secretions that are produced while a person coughs, sneezes talk or even breathes. Symptoms were observed between 4-14 days after exposure to the virus. While symptoms of pneumonia were seen in many, some atypical manifestations were also observed making prognostic assessment difficult.

The virus is thought to enter the body by binding to ACE 2 receptors. The density of these receptors seems to be particularly high in the respiratory tract, while they are also found in the cardia and the gastrointestinal system. Symptoms that patients present with range from a flu like illness, diarrhea, pneumonia to even acute clotting related symptoms such as myocardial infarction or a stroke or a pulmonary embolism. Most patients suffering from the disease seem to have a relatively benign course of illness 
while nearly $20 \%$ of all infected contribute significantly to morbidity and mortality. As the pandemic rages on, numerous mutations of the virus have made it all the more virulent and infective. The sheer patient load during the peak of each wave necessitated the development of a quick and comprehensive triaging system that would be able to assist in prognosis assessment and thereby help to identify those at most need for medical attention.

As we learnt more about the virus and the cytokine storm presentation in some, it was imperative to identify early signs of the same and institute treatment immediately to prevent complications. Cytokine storm is a hyperimmune response to the antigen and usually presents in the second week of illness. This is mainly associated with very rapid disease progression and deterioration in patients and necessitates urgent intervention. Early triaging and institution of treatment has been seen to significantly alter the course of illness. ${ }^{2,3}$

Pneumonia scoring systems such as PSI and CURB 65 were inadequate to assess disease prognosis due to a multi system involvement of the virus. ${ }^{4}$ The aim of this study was to develop one such system that could incorporate clinical, biochemical and radiological parameters that were found to be directly related to the severity of illness.

\section{Materials and Methods}

This retrospective study is based on health records of 138 confirmed Covid19 patients admitted in Raja Rajeshwari Medical College and Hospital, from August 2020 to September 2020. COVID 19 infection was confirmed by a nasopharyngeal swab via RT PCR. This study was conducted in accordance with the principles of Helsinki and Ethical clearance was obtained from the institutional ethics committee of Rajarajeswari Medical College and Hospital (No: RRMCH IEC/02/2021-22)

Patients were treated in accordance with guidelines formulated by the Government of India ${ }^{5}$. Retrospective analysis of health records of patients admitted in our hospital was carried out to identify characteristics that were contributing to morbidity and mortality due to the disease. Literature survey was also done to provide scientific backing for the parameters that were identified. Clinical parameters on admission such as Age, Co-morbidities, Pulse Rate, Respiratory Rate, BP, Temperature, Saturation were noted and analyzed. Biochemical parameters such as Neutrophil Lymphocyte ratio (NLR), D Dimer, Creatinine, ALT, Trop I was also noted. CT Scoring was done for the inpatients based on lobe involvement. A scoring system was also developed for X-Rays. All data was collected from tests that were already done with no additional cost borne by the patient.

Scores were assigned to each parameter. A cumulative score was calculated and a cut off value identified for risk stratification. The cut offs were identified on the basis of a pilot study conducted on a smaller cohort. All enrolled subjects were assigned one of two outcomes- discharge or death. The outcome that was assigned to each patient was compared to the triaging assessment based on the scoring system. The scoring system has been tabulated in Table 1.

\section{ANALYSIS AND STATISTICAL METHODS}

Statistical analysis of the categorical data was done using Chi square test and descriptive analysis. Statistical test differences were considered significant if the $P$ values were $<0.05$ The prognostic accuracy of the scoring system was

\begin{tabular}{|c|c|c|}
\hline PARAMETER & VALUE & SCORE \\
\hline \multirow[t]{3}{*}{ Comorbidity } & None & 0 \\
\hline & 1 & 1 \\
\hline & $>1$ & 2 \\
\hline $\begin{array}{l}\text { Shortness of } \\
\text { breath }\end{array}$ & $<2$ & 0 \\
\hline$(\mathrm{mMRC})$ & $>=2$ & 1 \\
\hline \multirow[t]{2}{*}{ Temperature (F) } & $<99$ & 0 \\
\hline & $>=99$ & 1 \\
\hline \multirow[t]{3}{*}{ Saturation (\%) } & $>94$ & 0 \\
\hline & $81-94$ & 1 \\
\hline & $=<80$ & 2 \\
\hline \multirow{3}{*}{ Pulse (bpm) } & $<50$ & $1 \mathrm{~b}$ \\
\hline & $=>100$ & $1 \mathrm{t}$ \\
\hline & $50-99$ & 0 \\
\hline \multirow{2}{*}{$\begin{array}{l}\text { Respiratory rate } \\
(\mathrm{cpm})\end{array}$} & $<22$ & 0 \\
\hline & $>=22$ & 1 \\
\hline \multirow[t]{2}{*}{ D Dimer (mcg/ml) } & $<5$ & 0 \\
\hline & $>5$ & 1 \\
\hline \multirow[t]{2}{*}{ Counts (NLR) } & $<3.13$ & 0 \\
\hline & $>=3.13$ & 1 \\
\hline \multirow[t]{2}{*}{ Trop I (ng/mL) } & $<0.41$ & 0 \\
\hline & $>0.41$ & 1 \\
\hline \multirow[t]{4}{*}{ Organ } & Normal RFT\&LFT & 0 \\
\hline & Creatinine $>0.9$ & $1 \mathrm{r}$ \\
\hline & ALT $>120$ & 11 \\
\hline & Both are deranged & 2 \\
\hline \multicolumn{3}{|l|}{ Radiology } \\
\hline CT & $<9$ & 0 \\
\hline \multirow[t]{2}{*}{ (OR) } & $9-16$ & 1 \\
\hline & $=>16$ & 2 \\
\hline \multirow[t]{3}{*}{ Xray } & No features & 0 \\
\hline & $\begin{array}{l}\text { Infiltrates with non COVID } \\
\text { features }\end{array}$ & 1 \\
\hline & $\begin{array}{l}\text { Infiltrates with features } \\
\text { consistent with COVID }\end{array}$ & 2 \\
\hline \multirow[t]{2}{*}{ Age (50) } & $<50$ & 0 \\
\hline & $>=50$ & 1 \\
\hline \multirow{3}{*}{$\begin{array}{l}\text { Cumulative risk } \\
\text { assessment }\end{array}$} & $<5$ & Mild \\
\hline & $5-7$ & Moderate \\
\hline & $8-16$ & Severe \\
\hline
\end{tabular}


done by determining the area under the curve of the ROC. Analyses were performed with the SPSS software v25.5.

\section{RESULTS}

Out of the 138 patients, 103 were discharged and 35 died. The overall mortality rate was $25.4 \%$.

The results have been tabulated in the form of Table 2 .

Figure 1 demonstrates that a higher percentage of the survivors had no comorbidities and that higher co

\begin{tabular}{|c|c|c|c|}
\hline \multirow[t]{2}{*}{ Characteristics } & \multicolumn{2}{|c|}{ Outcome } & \multirow[t]{2}{*}{ P Value } \\
\hline & $\begin{array}{l}\text { Discharge } \\
\quad(103)\end{array}$ & Death (35) & \\
\hline \multicolumn{4}{|l|}{ Co Morbidities } \\
\hline No co morbidity $(0)$ & $57(55.4)$ & $09(25.8)$ & \multirow[t]{3}{*}{0.010} \\
\hline One co morbidity (1) & $23(22.3)$ & $13(37.1)$ & \\
\hline $\begin{array}{l}\text { More than one co- } \\
\operatorname{morb}(2)\end{array}$ & $23(22.3)$ & 13(37.1) & \\
\hline \multicolumn{4}{|l|}{$\mathrm{SOB}$} \\
\hline 0 & $29(28.2)$ & $01(2.9)$ & \multirow[t]{2}{*}{0.002} \\
\hline 1 & $74(71.8)$ & $34(97.1)$ & \\
\hline \multicolumn{4}{|l|}{ Temp } \\
\hline 0 & $101(98.1)$ & $34(97.1)$ & \multirow[t]{2}{*}{0.748} \\
\hline 1 & $02(1.9)$ & $01(2.9)$ & \\
\hline \multicolumn{4}{|l|}{$\mathrm{SPO}_{2}$} \\
\hline $0^{2}$ & $32(31.1)$ & $0(0.0)$ & \multirow[t]{3}{*}{0.0001} \\
\hline 1 & $47(45.6)$ & $10(28.6)$ & \\
\hline 2 & $24(23.3)$ & $25(71.4)$ & \\
\hline \multicolumn{4}{|l|}{ PR } \\
\hline 0 & $62(60.2)$ & $09(25.7)$ & \multirow[t]{2}{*}{0.0001} \\
\hline 1 & $41(39.8)$ & $26(74.3)$ & \\
\hline \multicolumn{4}{|l|}{$\mathrm{RR}$} \\
\hline 0 & $62(60.2)$ & 04(11.4) & \multirow[t]{2}{*}{0.0001} \\
\hline 1 & $41(39.8)$ & $31(88.6)$ & \\
\hline \multicolumn{4}{|l|}{ Dimer } \\
\hline 0 & $18(17.5)$ & $02(5.7)$ & \multirow[t]{2}{*}{0.088} \\
\hline 1 & $85(82.5)$ & $33(94.3)$ & \\
\hline \multicolumn{4}{|l|}{ NLR } \\
\hline 0 & $39(37.9)$ & $01(2.9)$ & \multirow[t]{2}{*}{0.0001} \\
\hline 1 & $64(62.1)$ & $34(97.1)$ & \\
\hline \multicolumn{4}{|l|}{ Trop I } \\
\hline 0 & $103(100.0)$ & $34(97.1)$ & \multirow[t]{2}{*}{0.085} \\
\hline 1 & $0(0.0)$ & $01(2.9)$ & \\
\hline \multicolumn{4}{|l|}{ Organ } \\
\hline 0 & $83(80.6)$ & $25(71.4)$ & \multirow[t]{3}{*}{0.257} \\
\hline 1 & $20(19.4)$ & $10(28.6)$ & \\
\hline 2 & 0 & 0 & \\
\hline \multicolumn{4}{|l|}{ Radio } \\
\hline 0 & $13(12.6)$ & 04(11.4) & 0.016 \\
\hline 1 & $50(48.5)$ & $08(22.9)$ & \\
\hline 2 & $40(38.8)$ & $23(65.7)$ & \\
\hline Age & & & \\
\hline 0 & $56(54.4)$ & $06(17.1)$ & 0.0001 \\
\hline 1 & $47(45.6)$ & $29(82.9)$ & \\
\hline Category & & & \\
\hline Mild & $26(25.2)$ & $0(0.0)$ & 0.0001 \\
\hline Moderate & $38(36.9)$ & $02(5.7)$ & \\
\hline Severe & $39(37.9)$ & $33(94.3)$ & \\
\hline
\end{tabular}

Asian Journal of Medical Sciences | Sep 2021 | Vol 12 | Issue 9 morbidity score was associated with mortality. The comorbidities observed in this cohort of patients included Diabetes Mellitus as the most common followed by Hypertension, Hypothyroidism, Chronic Obstructive airway diseases, Tuberculosis, HIV, Myasthenia Gravis, Ischemic heart disease.

Figure 2 compares the occurrence of abnormal clinical parameters in both outcomes. As is evident from the chart, abnormal clinical data was associated with mortality.

$78.3 \%$ of the population came with higher grades of shortness of breath on presentation. Shortness of breath was also the most commonly observed symptom in the cohort.

$48.6 \%$ patients were found to have pulse rate abnormalities. These patients were found to have a higher mortality rate. $52.2 \%$ of patients were found to have tachypnea on presentation.

Raised temperature was recorded in a very small subset of patients and therefore could not be used to derive a correlation with clinical outcome.

Figure 3 shows the occurrence of abnormalities in the biochemical parameters across the whole of the study group.

$\mathrm{D}$ dimer was found to be above the assigned cut off in $85.5 \%$ patients. NLR was found to be higher in $71 \%$ of the population and increasing values were found to be an important marker of mortality. Trop I was found to be elevated in only one patient in the study. (The patient was

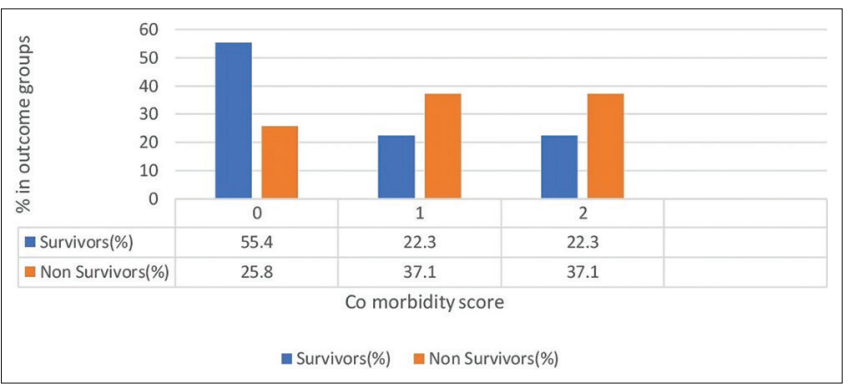

Figure 1: Comorbidity vs outcome of the patients

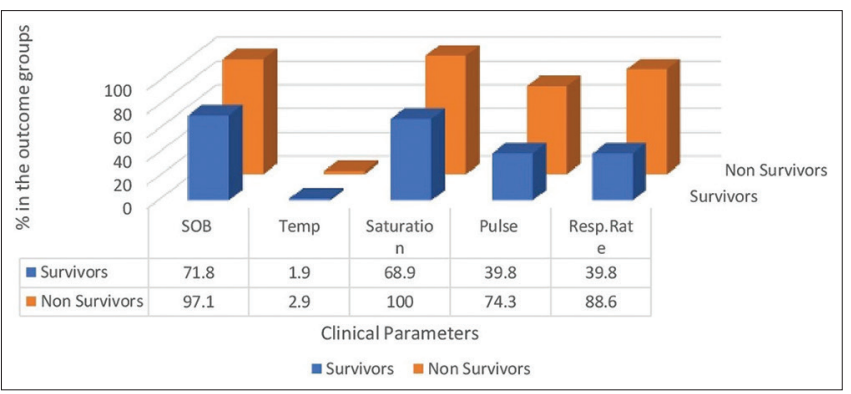

Figure 2: Clinical parameter abnormalities vs outcome 
assigned death as outcome). Organ injury was assessed with respect to renal (Creatinine) and liver function (ALT). $21.7 \%$ of the population was observed to have organ injury with renal injury more commonly observed than hepatic injury.

Figure 4 shows the occurrence of biochemical abnormalities plotted against the $\%$ of those in the respective outcome groups. It shows that the occurrence of these abnormalities is significantly higher in the non-survivor group and it is therefore imperative to include these in routine evaluation of patients.

Radiological imaging to assess severity of lung injury was done and mortality rate found to increase with increasing CT severity scoring as is evident in Figure 5.

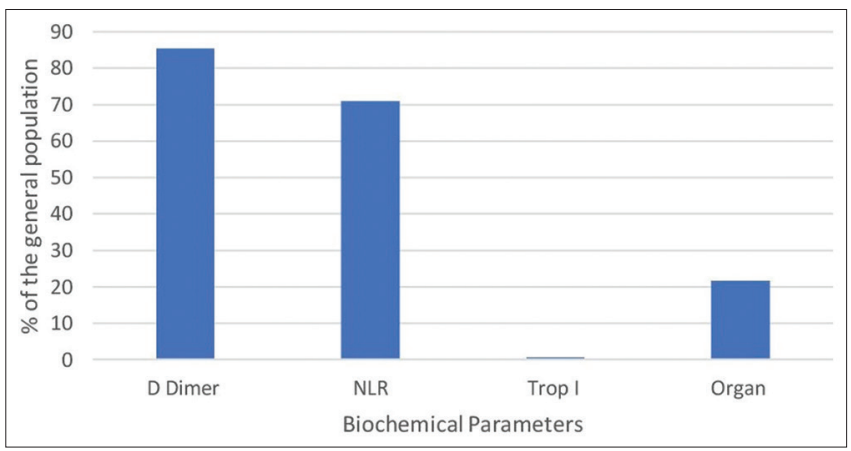

Figure 3: Biochemical parameters of the patients

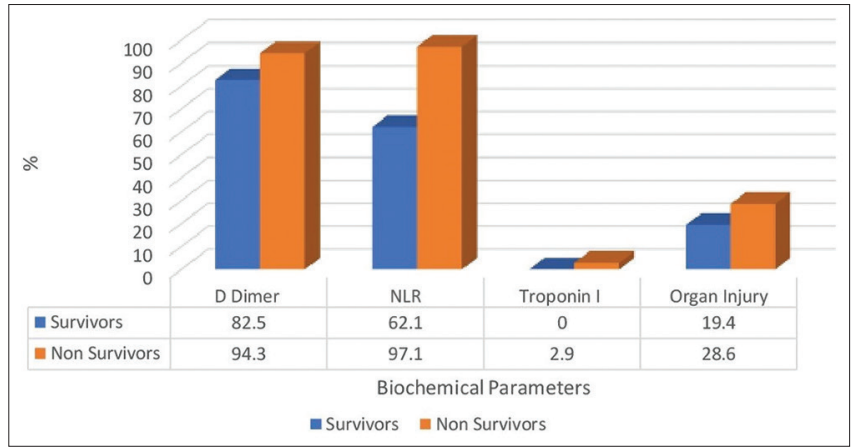

Figure 4: Biochemical abnormalities vs outcome

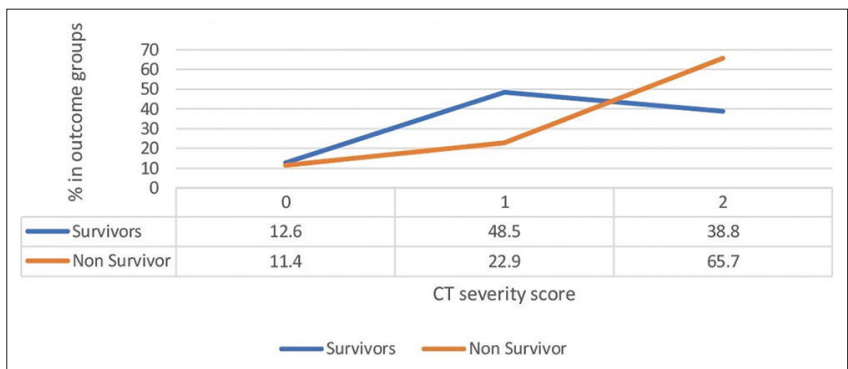

Figure 5: CT severity score vs outcome
The cumulative score across the parameters ranged from 0-16. These were classified into mild (0-4), moderate (5-7) and severe (8-16). Figure 6 shows increasing severity of disease with increasing score and categorization.

Figure 7 shows the ROC Curve as a predictor of prognostic accuracy of the model. (AUC $=0.875$ ).

\section{DISCUSSION}

This study was carried out with the aim of establishing an effective scoring system that could be used for identifying patients at a risk for mortality.

In our study $74.28 \%$ non survivors were found to have comorbidities with Hypertension being the most common. Presence of comorbidity therefore acted as an important

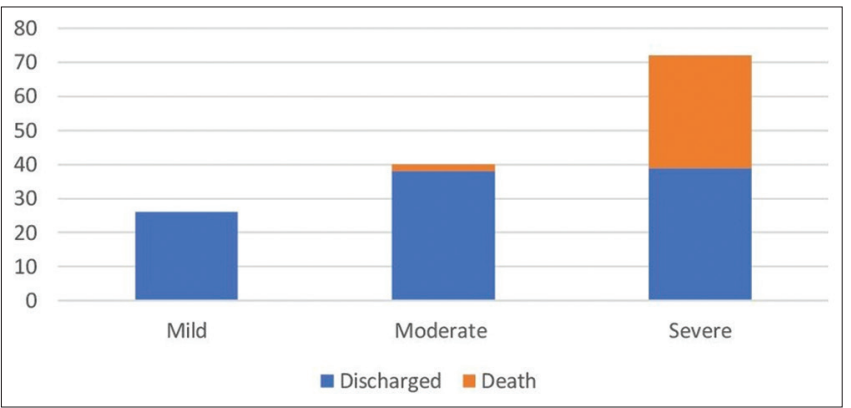

Figure 6: Outcome vs risk category

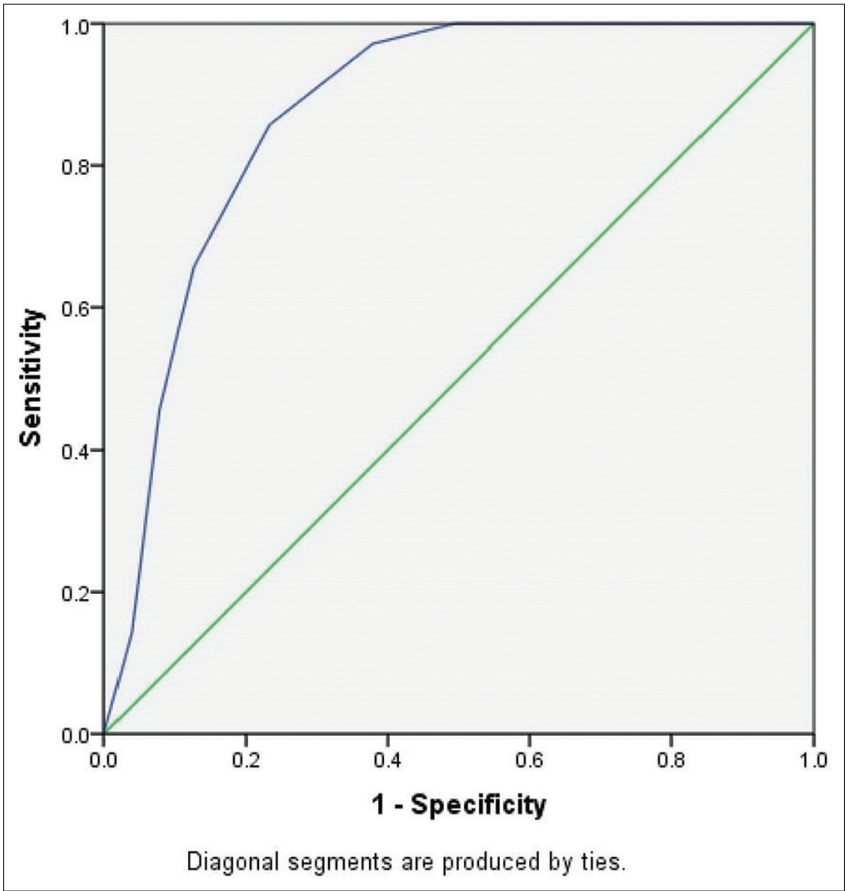

Figure 7: ROC to assess the prediction accuracy of the model 
risk factor for worser outcomes. Studies carried out in India by Jaseela Majeed et al., on 206 deceased patients showed that $50.5 \%$ of the deceased had preexisting co morbidities, with Diabetes and Hypertension being the most commonly seen $^{6}$. Another study carried out in central India by Dosi $\mathrm{R}$ et al., on 365 patients admitted in a tertiary care center described $47.1 \%$ of the population as having co-morbidities and Hypertension was the most commonly seen ${ }^{7}$. A metaanalysis done by Wern Hann NG et al., on 150 articles from April to September 2020 revealed Chronic Kidney Disease, Diabetes Mellitus, Hypertension to be individually linked to mortality from COVID $19 .^{8}$

Shortness of Breath as a subjective indicator of lung injury was also considered using modified Medical Research Council scoring system. About $28.1 \%$ survivors had a scoring of 1 indicative of severe breathlessness while $97.1 \%$ of those in the non-survivor group had the same initial presentation. Shortness of breath was therefore found to be directly associated with outcome. A meta-analysis of all articles with dyspnea and fever was carried out by $\mathrm{Li}$ Shi, Yin Wang, et al., wherein all articles up to May 12020 were studied. ${ }^{9}$ The inferences drawn was that dyspnea was found to be significantly associated with higher mortality in COVID19 patients on the basis of 11 studies with 2091 cases. A retrospective study done on clinical features of 85 fatal cases of COVID 19 from Wuhan showed that nearly 60\% patients had SOB and that an early onset of SOB seemed to be a risk factor for mortality. ${ }^{10}$

Saturation at room air was also found to directly correlate with the course of illness with $100 \%$ of non survivors presenting with lower saturation. Mortality was found to be the highest in those with a score of 2 corresponding to a saturation less than 80 . It was in most cases also found to directly correspond to the subset of patients presenting with breathlessness. Silent hypoxemia being an integral part of the disease progression required oxygen saturation to be an important prognostic marker independent of the subjective sensation of breathlessness felt by the patient.

A study done in Geneva on 83 patients of COVID19 found that less than $50 \%$ of patients had dyspnea which was associated with bad prognosis. As most are not able to actively perceive dyspnea, it was important to assess Respiratory Rate as well as pulse oximetry as adjuvant tools in assessing hypoxemia. In a study done by Mattia Busana et al., it was found that nearly $25 \%$ of the study population who had radiologically severe disease presented with no signs suggestive of respiratory failure and found to be hypoxemic on pulse oximetry. ${ }^{11}$ This evidence of happy hypoxemia in COVID demonstrates the need for pulse oximetry to be an important measure.
Temperature $>37.2 \mathrm{C}$ was assessed as a measure of fever. Tharakan et al., found a trend of increased mortality with poor temperature control in severely ill COVID19 patients. ${ }^{12}$ They found that one in three patients with a maximum body temperature above $39.5 \mathrm{C}$ died. The study suggests that poor body temperature control during the course of illness is associated with mortality and morbidity. A letter to the editor by Anne M Drewry et al., in the Critical Care journal in response to the article by Tharaka et al., found that contrary to the findings in the aforementioned study, there was a proven benefit in raised body temperatures in overcoming the disease. ${ }^{13} \mathrm{~A}$ study done in Daegu, Korea on 110 hospitalized patients found temperature beyond $37 \mathrm{C}$ to be an independent risk factor for mortality from COVID $19 .{ }^{14}$ While we acknowledge the need to include body temperature as an important marker of COVID cytokine storm, we were unable to establish a direct correlation with outcome in this study.

Pulse rate abnormalities have been found to be associated with worsening outcomes, with both bradycardia and tachycardia being independent markers of complications. In this study we assigned a separate scoring nomenclature for bradycardia (1b) and tachycardia(1t). Overall, $74.3 \%$ of non survivors were found to have rate disturbances with tachycardia being more prominent. A study done by Lijuan Hu on patients with severe illness analyzed bradycardia as an important risk factor for sudden death. ${ }^{15}$ This study postulated that bradycardia could be a red flag indicative of viral myocarditis and should therefore be an important consideration in patients. A study done by Qingxing Chen et al., on 54 critically ill COVID 19 patients to assess cardiovascular complications associated with the disease revealed sinus tachycardia to be an important risk factor for mortality. ${ }^{16}$ The incidence of Pulmonary embolism in those with COVID has been found to be $2.6-8.9 \%$, therefore it is imperative to consider tachycardia to be an indicator of worsening prognosis.

To assess the non-pulmonary systemic involvement, extensive literature survey was done in order to identify parameters that were indicative of the pathogenesis and extent of systemic involvement of the virus. These were also parameters that were included as a part of routine evaluation of the patient.

Coronavirus disease as an exception to other viruses presented in most with neutrophilia and the NLR was found to be directly related to the severity of illness. We found in our study that the higher NLR was found associated with prolonged hospital stay and mortality. Neutrophil-Lymphocyte ratio was also assessed in line with current data on rising trends in NLR associated with COVID 19. We found $97.1 \%$ of non survivors had elevated NLR in this study. Lymphocytopenia developed in 38\% 
of all patients and in $76 \%$ of critically ill patients. A study done in Shanghai, China by Min Cao, Dandan Zhang, et al., found that out of 198 patients lymphopenia was found in $45.8 \%$ patients. ${ }^{17}$ Studies done by Jingyuan Liu showed NLR and older age to be independent risk factors. ${ }^{18}$ The threshold value for NLR across the studies done was 3.13.

NLR was also found to be a low-cost marker as compared to cytokines as a marker of systemic inflammation and is therefore a good prognostic tool. The severity of injury to the lungs or organs correlated with neutrophil infiltration of lungs and in the peripheral blood, therefore NLR may be a useful factor in determining the inflammation and severity.

Covid has been found to be associated with activation of the coagulation cascade and D Dimer has been found to be the most directly related marker of the same. This has been thought to be an indirect indicator of the cytokine storm and therefore is an important prognostic marker. This is also serving as an important biomarker in assessing severity and is being followed up serially in patients even in the post covid illness period. Lymphopenia in particular has been associated with ICU stay.

We found D Dimer to be associated with higher mortality with $94.3 \%$ of non survivors with higher values. This finding was in line with the literary survey. Litao Zhang et al., performed a study on 346 inpatients, 67 of those had D dimer of more than fourfold rise. ${ }^{19} \mathrm{~A}$ higher level of D Dimer was found to correlate with a higher risk of mortality. A pooled analysis done by Guiseppe Lippi postulated D dimer to be a marker for DIC associated with COVID 19. ${ }^{20}$ They found a 9-level rise in d dimer values of those patients that had died. Early institution of anticoagulant therapy has been found to greatly benefit patients of severe COVID, it is therefore an important early screening tool in preventing morbidity.

It was found that most people who died from Covid were found to have endothelitis involving many organs. The unregulated immune system response associated with the cytokine storm led to significant organ damage. ${ }^{21}$

It has been seen that disruption of the ACE 2 receptor has been found to be associated with myocardial injury and dysfunction, Troponin I and T have been found to be surrogate markers for myocardial injury. Troponin I have been found to have the highest sensitivity in the first 24 hours of hospitalization and has been found to be directly associated with morbidity and mortality. ${ }^{22}$ In this particular study we were unable to establish a direct correlation between Trop I and outcome. We however do feel the necessity of adding a cardiac marker to the scoring system for instituting timely intervention, as was also reiterated in the Literature survey.

Organ injury as a parameter involved either liver or kidney impairment or both organ impairment. The cut off values used in the assessment of the same were decided upon after extensive literature search. A study done in Shanghai, China by Min Cao et al., found that out of 198 patients nearly $9.6 \%$ were admitted to the ICU because of the development of organ dysfunction. ${ }^{23}$

Acute renal injury was seen in those with severe disease reflecting the extensive cytokine storm and endothelitis involving the kidney. AKI was found to be multi factorial with not just the virus causing it, but also presence of other factors such as older age, co morbidities. ${ }^{24}$ Creatinine was taken as a marker of renal injury with a threshold value of 0.9 ; it was also found to be an independent marker of disease severity and increased levels found in those with prolonged ICU stay. ${ }^{25}$ Variation in serum creatinine levels over a $24-48$ hour period has been an important indicator of acute renal failure. Study done by Gaetano Alfano et al, found that variability in serum creatinine over a $24 \mathrm{hr}$ period in hospitalized patients of COVID 19 was an independent risk factor associated with poorer outcomes. ${ }^{26}$

A systematic review was carried out by Samuel Atila Rodrigues et al, which found that acute renal injury was prevalent in those that died of COVID 19. ${ }^{27}$ Another metaanalysis done by Wenjie Tian et al involving 4659 patients in 14 studies observed that multiple biomarkers on admission including troponin I, Creatine, ALT, were found to be significantly elevated in those that died. ${ }^{28}$ We found that $28.6 \%$ of non survivors had organ injury.

Liver injury has also been extensively studied in relation to COVID 19. Initially, it was hypothesized that as ACE 2 receptors are seen in cholangiocytes, cholangiocytic injury may occur as a result of viral infiltration and endothelitis. However, ALP, a marker of cholangiocyte injury was within normal range and it was found that ALT, AST were found to be elevated, implying parenchymal injury. While the exact mechanism of injury is not understood and more work needs to be done in this area, immune mediated tissue injury is found to play an important role in severity of illness. This elevation was also found to correspond to increased neutrophil and lymphopenia. ${ }^{29}$ A retrospective study on 148 patients in Shanghai Public Health Centre during the month of Jan 2020 revealed that $37 \%$ of the patients had abnormal liver function mainly liver enzymes, this was also associated with prolonged hospital stay. Liver enzymes were seen to be elevated beyond 3-5 times the upper limit of normal. ${ }^{30}$ In our study, the threshold cut 
off for liver injury was considered as 3 times the upper limit of normal.

For an assessment of the lung injury in patients with COVID 19, radiology was incorporated as one of the parameters in the scoring system.

While CT was definitely a more reliable imaging technique to assess severity, critically ill patients will not be able to be assessed using a CT and a portable Xray could be an alternative, even in clinical settings with limited infrastructure. We therefore created a scoring system based on Xray findings in order to assess severity. In this study, however, we were unable to validate the Xray scoring system as CT had been already used in the subjects. CT severity scoring as described by Yang et al has been used in the scoring of the lung involvement in these patients based on lobe involvement. ${ }^{31}$

A review done by Di Dong et al on role of imaging in COVID emphasizes on the need for CT to assess lung involvement and that use of CT in conjunction with biomarkers will better help in assessment of severity.32 Hyunjoon W Kim et al., conducted a study on the role of $\mathrm{X}$ Rays in triaging in the emergency department using a scoring system based on Xray involvement of the lung. ${ }^{33}$ Four hundred patients were reviewed in this study and Xray scoring was found to be associated with prolonged hospital stay and need for intubation.

The last parameter to be assessed is age and the cutoff for the purpose of assigning a score was taken as $50 \mathrm{yrs}$. Studies across the world have demonstrated age above 50 to be a significant risk factor for mortality due to Covid 19. This may be in part also attributed to the fact that patients above this age are more likely to have co-morbidities which further worsen the disease. In a meta-analysis done by Biswas $\mathrm{M}$ et al, it was found that those with age $\geq 50$ yrs. were found to have 15.4 folds increased mortality as compared to those under the age of $50 .{ }^{34}$ In our study $82.9 \%$ of the non survivors were aged above 50 .

The overall score was calculated and the final outcome was recorded. It was found that risk of mortality was also found to be higher in those triaged with severe illness as per our scoring model. $5.7 \%$ of the fatalities occurred in the moderate category and $94.8 \%$ in the severe category. There was no mortality observed in the mild category.

We acknowledge that however efficacious the model is, it has its own limitations. The study has been done in a single center with a limited study population and we recognize that the model will have to be validated in a larger cohort. Certain parameters though of paramount importance in the assessment of covid 19 associated illness were not validated significantly in this study, we do however hope to validate them in future studies. Considering the study period during which it was carried out, all participants in the study were unvaccinated and we do recognize the bearing that vaccination has on altering the course of illness and hope to incorporate it into future validations.

The $\mathrm{p}$ value for the study was found to be 0.0001 and is therefore significant. Model performance was evaluated based on ROC analysis and the model was found to show great prognostic accuracy (AUC $=0.875$ ). The sensitivity and specificity associated is 0.857 and 0.767 respectively.

We believe therefore that this model will serve as an effective triaging and risk stratification system which will better aid in early and comprehensive management of COVID 19 related illnesses.

\section{CONCLUSION}

With this scoring system we hope to enable healthcare workers to be able to carry out an accurate and comprehensive assessment of the prognosis of patients with COVID 19 illness and thus institute early aggressive treatment in those with a higher risk for mortality. All the parameters included in the scoring system are a part of routine evaluation of the patient and should therefore be implementable in all healthcare settings.

\section{ACKNOWLEDGEMENT}

The authors take this opportunity to thank the Department of Pulmonary Medicine, Rajarajeswari Medical College and Hospital, Bangalore. Special mention to Mr. Vishwanath for assistance in statistical analysis and interpretation.

\section{REFERENCES}

1. Phelan AL, Katz R, Gostin LO. The Novel Coronavirus Originating in Wuhan, China. JAMA. 2020;323(8):709.

https://doi.org/10.1001/jama.2020.1097

2. Chen M, Tu C, Tan C, Zheng X, Wang X, Wu J, et al. Key to successful treatment of COVID-19: accurate identification of severe risks and early intervention of disease progression. Cold Spring Harbor Laboratory. 2020; https://doi.org/10.1101/2020.04.06.20054890

3. Wu J, Li W, Shi X, Chen Z, Jiang B, Liu J, et al. Early antiviral treatment contributes to alleviate the severity and improve the prognosis of patients with novel coronavirus disease (COVID-19). Journal of Internal Medicine. 2020; 288(1):128-138. https://doi.org/10.1111/joim.13063

4. Satici C, Demirkol MA, Sargin Altunok E, Gursoy B, Alkan M, 
Kamat $\mathrm{S}$, et al. Performance of pneumonia severity index and CURB-65 in predicting 30-day mortality in patients with COVID-19. International Journal of Infectious Diseases. 2020; 98:84-89.

https://doi.org/10.1016/j.ijid.2020.06.038

5. http://icmr.gov.in

6. Majeed J, Ajmera P and Goyal RK. Delineating clinical characteristics and comorbidities among 206 COVID-19 deceased patients in India: Emerging significance of renin angiotensin system derangement. Diabetes Research and Clinical Practice. 2020; 167:108349.

https://doi.org/10.1016/j.diabres.2020.108349

7. Jain R, Garg R, Sodani A, Chouksey D, Dosi R, Athale S, et al. Neurological Symptoms as Initial Manifestation of Covid-19 - An Observational Study. Annals of Indian Academy of Neurology. 2020; 0(0):0.

https://doi.org/10.4103/aian.AIAN_560_20

8. Ng WH, Tipih T, Makoah NA, Vermeulen J-G, Goedhals D, Sempa JB, et al. Comorbidities in SARS-CoV-2 Patients: A Systematic Review and Meta-Analysis. American Society for Microbiology. 2021;12(1).

https://doi.org/10.1128/mBio.03647-20

9. Shi $L$, Wang $Y$, Wang $Y$, Duan $G$ and Yang $H$. Dyspnea rather than fever is a risk factor for predicting mortality in patients with COVID-19. Journal of Infection. 2020; 81(4):647-679.

https://doi.org/10.1016/j.jinf.2020.05.013

10. Du Y, Tu L, Zhu P, Mu M, Wang R, Yang P, et al. Clinical Features of 85 Fatal Cases of COVID-19 from Wuhan. A Retrospective Observational Study. American Journal of Respiratory and Critical Care Medicine. 2020: 201(11):1372-1379.

https://doi.org/10.1164/rccm.202003-05430C

11. Busana M, Gasperetti A, Giosa L, Forleo GB, Schiavone M, Mitacchione G, et al. Prevalence and outcome of silent hypoxemia in COVID-19. Minerva Anestesiol. 2021; https://doi.org/10.23736/S0375-9393.21.15245-9

12. Tharakan S, Nomoto K, Miyashita S and Ishikawa K. Body temperature correlates with mortality in COVID-19 patients. Critical. 2020;24(1).

https://doi.org/10.1186/s13054-020-03045-8

13. Drewry AM, Hotchkiss R and Kulstad E. Response to Body temperature correlates with mortality in COVID-19 patients. Critical Care. 2020;24(1).

https://doi.org/10.1186/s13054-020-03186-w

14. Jang JG, Hur J, Choi EY, Hong KS, Lee W and Ahn JH. Prognostic Factors for Severe Coronavirus Disease 2019 in Daegu, Korea. Journal of Korean Medical Science. 2020;35(23). https://doi.org/10.3346/jkms.2020.35.e209

15. Hu L, Gong L, Jiang Z, Wang Q, Zou Y and Zhu L. Clinical analysis of sinus bradycardia in patients with severe COVID-19 pneumonia. Critical Care. 2020; 24(1).

https://doi.org/10.1186/s13054-020-02933-3

16. Chen Q, Xu L, Dai Y, Ling Y, Mao J, Qian J, et al. Cardiovascular manifestations in severe and critical patients with COVID-19. Clinical Cardiology. 2020;43(7):796-802.

https://doi.org/10.1002/clc.23384

17. Cao M, Zhang D, Wang Y, Lu Y, Zhu X, Li Y, et al. Clinical Features of Patients Infected with the 2019 Novel Coronavirus (COVID-19) in Shanghai, China. Cold Spring Harbor Laboratory; 2020. https://doi.org/10.1101/2020.03.04.20030395

18. Liu J, Liu Y, Xiang P, Pu L, Xiong H, Li C, et al. Neutrophil-tolymphocyte ratio predicts critical illness patients with 2019 coronavirus disease in the early stage. Journal of Translational
Medicine. 2020; 8(1).

https://doi.org/10.1186/s12967-020-02374-0

19. Zhang L, Yan X, Fan Q, Liu H, Liu X, Liu Z, et al. D-dimer levels on admission to predict in-hospital mortality in patients with Covid-19. Journal of Thrombosis and Haemostasis. 2020;18(6):1324-1329.

https://doi.org/10.1111/jth.14859

20. Lippi $G$ and Favaloro EJ. D-dimer is Associated with Severity of Coronavirus Disease 2019: A Pooled Analysis. Thrombosis and Haemostasis.2020;120(05):876-878. https://doi.org/10.1055/s-0040-1709650

21. Bhaskar S, Sinha A, Banach M, Mittoo S, Weissert R, Kass JS, et al. Cytokine Storm in COVID-19-Immunopathological Mechanisms, Clinical Considerations, and Therapeutic Approaches: The REPROGRAM Consortium Position Paper. Frontiers in Immunology. 2020;11. https://doi.org/10.3389/fimmu.2020.01648

22. Babapoor-Farrokhran S, Gill D, Walker J, Rasekhi RT, Bozorgnia $B$ and Amanullah A. Myocardial injury and COVID-19: Possible mechanisms. Life.2020;253:117723.

https://doi.org/10.1016/j.lfs.2020.117723

23. Cao M, Zhang D, Wang Y, Lu Y, Zhu X, Li Y, et al. Clinical Features of Patients Infected with the 2019 Novel Coronavirus (COVID-19) in Shanghai, China. Cold Spring Harbor Laboratory; 2020. https://doi.org/10.1101/2020.03.04.20030395

24. Hirsch JS, Ng JH, Ross DW, Sharma P, Shah HH, Barnett RL, et al. Acute kidney injury in patients hospitalized with COVID-19. Kidney International. 2020; 98(1):209-218. https://doi.org/10.1016/j.kint.2020.05.006

25. Wu J, Shi L, Zhang $P$, Wang $Y$ and Yang $H$. Is creatinine an independent risk factor for predicting adverse outcomes in COVID-19 patients? Transplant Infectious Disease. 2020; 23(2). https://doi.org/10.1111/tid.13539

26. Alfano G, Ferrari A, Fontana F, Mori G, Ligabue G, Giovanella S, et al. Twenty-four-hour serum creatinine variation is associated with poor outcome in the novel coronavirus disease 2019 (COVID-19) patients. Kidney Research and Clinical Practice. 2021; 40(2):231-240. https://doi.org/10.23876/j.krcp.20.177

27. Nogueira SÁR, Oliveira SCS de, Carvalho AFM de, Neves JMC, Silva LSV da, Silva Junior GB da, et al. Renal changes and acute kidney injury in covid-19: a systematic review. Revista da Associação Médica Brasileira. 2020; 66(suppl 2):112-117. https://doi.org/10.1590/1806-9282.66.s2.112

28. Tian W, Jiang W, Yao J, Nicholson CJ, Li RH, Sigurslid HH, et al. Predictors of mortality in hospitalized COVID-19 patients: A systematic review and meta-analysis. Journal of Medical Virology. 2020;92(10):1875-1883.

https://doi.org/10.1002/jmv.26050

29. Kumar-M P, Mishra S, Jha DK, Shukla J, Choudhury A, Mohindra R, et al. Coronavirus disease (COVID-19) and the liver: a comprehensive systematic review and meta-analysis. Hepatology International. 2020;14(5):711-722. https://doi.org/10.1007/s12072-020-10071-9

30. Lei F, Liu Y, Zhou F, Qin J, Zhang P, Zhu L, et al. Longitudinal Association Between Markers of Liver Injury and Mortality in COVID-19 in China. Hepatology. 2020;72(2):389-398. https://doi.org/10.1002/hep.31301

31. Yang R, Li X, Liu H, Zhen Y, Zhang X, Xiong Q, et al. Chest CT Severity Score: An Imaging Tool for Assessing Severe COVID-19. Radiology: Cardiothoracic Imaging [Internet]. Radiological Society of North America (RSNA); 2020;2(2): 
e200047.

https://doi.org/10.1148/ryct.2020200047

32. Dong D, Tang Z, Wang S, Hui H, Gong L, Lu Y, et al. The Role of Imaging in the Detection and Management of COVID-19: A Review. IEEE Reviews in Biomedical Engineering [Internet]. Institute of Electrical and Electronics Engineers (IEEE); 2021; 14:16-29.

https://doi.org/10.1109/RBME.2020.2990959

33. Kim HW, Capaccione KM, Li G, Luk L, Widemon RS, Rahman O, et al. The role of initial chest X-ray in triaging patients with suspected COVID-19 during the pandemic. Emergency Radiology [Internet]. Springer Science and Business Media LLC; 2020;27(6):617-621.

https://doi.org/10.1007/s10140-020-01808-y

34. Biswas M, Rahaman S, Biswas TK, Haque Z and Ibrahim B. Association of Sex, Age, and Comorbidities with Mortality in COVID-19 Patients: A Systematic Review and Meta-Analysis. Intervirology [Internet]. S. Karger AG; 2020;64(1):36-47. https://doi.org/10.1159/000512592

\section{Authors Contribution:}

VG - Concept and design of study, interpreted results, reviewed literature and manuscript preparation; PS - Concept, coordination, interpreted results, reviewed

literature and manuscript preparation; MR - Reviewed literature and manuscript preparation.

\section{Work attributed to:}

Rajarajeswari Medical College and Hospital.

Orcid ID:

Dr Vivek Gundappa - (1) https://orcid.org/0000-0002-3644-3765

Dr Parinita Suresh - (D) https://orcid.org/0000-0002-7689-8959

Dr Manjari Rajagopalan - (1) https://orcid.org/0000-0002-5267-0829

Source of Support: Nil, Conflict of Interest: None declared. 